As we can see, the agreement with the desired value, $u(t)=1$, is excellent.

7. Discussion. Consider a system of renewal-type equations, given, say, in matrix form:

$$
X(t)=F(t)+\int_{0}^{t} K(t-s) X(s) d s .
$$

Equations of this type arise naturally in the study of multidimensional branching processes; see [6], [7].

If $X(t)$ is a $5 \times 5$ matrix, we are required to store 25 functions (i.e., the elements $\left.x_{i j}(t), i, j=1,2, \cdots, 5\right)$ if we proceed in the usual fashion. If high order accuracy were required-say, intervals of $10^{-3}$ over $0 \leqq t \leqq 5$-we would find that rapidaccess storage capacity would be exceeded.

On the other hand, if we use the foregoing technique, differential approximation of order 5 would lead to the task of solving about 250 simultaneous differential equations plus those required to determine $F(t)$. This is a simple matter for a modern computer. Furthermore, it is clear that we could use an approximation of order 10 without coming close to the storage capacity.

The RAND Corporation

Santa Monica, California

1. R. Bellman, J. Jacquez, R. Kalaba \& B. Kotkin, A Mathematical Model of Drug Distribution in the Body: Implications for Cancer Chemotherapy, The RAND Corporation Report No. RM-3463-NIH, February 1963.

2. R. Bellman \& R. Kalaba, Mathematical Trends in Control Theory, Dover Publications, New York. (To appear.)

3. R. Bellman, H. Kagiwada \& R. Kalaba, A Computational Procedure for Optimal System Design and Utilization, RAND Corporation Report No. RM-3174-PR, June 1962; also published in Proc. Nat. Acad. Sci. USA, V. 48, 1962, p. 1524-1528.

4. R. Bellman, "Mathematical model-making as an adaptive control process," Mathematical Optimization Techniques, University of California Press, Berkeley, 1963, p. 333-339.

5. C. Lanczos, Applied Analysis, Prentice-Hall, Englewood Cliffs, N. J., 1956.

6. T. E. Harris, Branching Processes, Ergebnisse der Math., Springer, Berlin, 1963.

7. R. Bellman \& K. L. Cooke, Differential-difference Equations, Academic Press, New York, 1963.

\title{
On the Numerical Solution of Equations of the Abel Type
}

\section{By Henry E. Fettis}

The integral equation known as Abel's has the general form

$$
f(x)=\int_{0}^{x} g(t)(x-t)^{-\alpha} d t
$$

where $\alpha$ is a real number, and

$$
0<\alpha<1 \text {. }
$$

Received August 20, 1963. 
The function $f(x)$ is supposed known and it is required to find the function $g(t)$. The solution is known to be [1]:

$$
g(x)=\frac{\sin (\alpha \pi)}{\alpha \pi}\left[\frac{d}{d x} \int_{0}^{x} f(t)(x-t)^{\alpha-1} d t\right] .
$$

Because of the singularity, the differentiation can not be carried out explicitly. However, if an integration by parts is first made, Equation (2) takes the form

$$
g(x)=\frac{\sin \alpha \pi}{\alpha \pi} \frac{d}{d x}\left[x^{\alpha} f(0)+\int_{0}^{x} f^{\prime}(t)(x-t)^{\alpha} d t\right],
$$

and if it is assumed that $f^{\prime}(t)$ is finite, the differentiation under the integral can be performed and we get

$$
g(x)=\frac{\sin \alpha \pi}{\pi}\left[f(0) x^{\alpha-1}+\int_{0}^{x} f^{\prime}(t)(x-t)^{\alpha-1} d t\right] .
$$

While both Equations (2) and (4) give the theoretically correct solution to Abel's equation, neither are suitable to compute from in problems where no explicit mathematical expression for $f(x)$ is known. First, there is the problem of the singular behavior of the integrand when $t=x$, and while this may be circumvented in several ways, either by an algebraic substitution which removes the singularity or by use of a quadrature formula which inherently takes into account the nature of the singularity (see e.g. [2]), there is an even greater barrier to the numerical problem, namely the fact that both expressions depend not on $f(x)$, but on its derivative. In fact, it is most often the case that $f(x)$ is obtainable only from measured data and, as is well known, the determination of accurate derivatives in such instances is extremely difficult, if not impossible. We, therefore, need a form of the solution in which $f^{\prime}(x)$ does not appear, and such a solution may readily be obtained if the integration by parts of Equation (4) is carried out in a somewhat different manner; namely, let

$$
\begin{aligned}
u & =(x-t)^{\alpha-1}, & d v & =f^{\prime}(t) d t, \\
d u & =-(\alpha-1)(x-t)^{\alpha-2} d t, & v & =f(t)-f(x) .
\end{aligned}
$$

Then, Equation (4) becomes

$$
\begin{aligned}
g(x)=\frac{\sin \alpha \pi}{\pi}\left\{f(0) x^{\alpha-1}-[f(t)\right. & -f(x)]\left[(x-t)^{\alpha-1}\right]_{0}^{x} \\
& \left.+(1-\alpha) \int_{0}^{x} \frac{f(x)-f(t)}{x-t}(x-t)^{\alpha-1} d t\right\}
\end{aligned}
$$

or

$$
g(x)=\frac{\sin \alpha \pi}{\pi}\left[x^{\alpha-1} f(x)+(1-\alpha) \int_{0}^{x} \frac{f(x)-f(t)}{x-t}(x-t)^{\alpha-1} d t\right] .
$$

It will be noted that while (6) inherently implies the existence of $f^{\prime}(x)$ in some sense in order that the $\operatorname{limit}_{t \rightarrow x}[(f(x)-f(t)) /(x-t)]$ be defined, it does not explicitly involve the derivative in any way. Thus, the only difficulty in evaluating Equation (6) numerically by quadrature would arise if it became necessary to 
evaluate the integrand at the point $t=x$. This would indeed be the case if a "closed" quadrature formula (i.e., one which involves the end points) were used. However, other quadrature formulae are available which do not require knowledge of the integrand except at interior points of the interval of integration, and, of these, perhaps the most suitable is the Gaussian type. Here the approximate value of the integral is expressed as a linear combination of the integrand (not including the singular term $\left.(x-t)^{\alpha-1}\right)$ evaluated at properly selected points and multiplied by appropriate weighting factors. (See e.g. [3].)

For this purpose, it is more convenient always to have a fixed interval of integration, and to this end we set

$$
t=x(1-u)
$$

and direct attention to the integral involved in Equation (6) in the form

$$
-\int_{0}^{1} \frac{f(x)-f[x(1-u)]}{u} u^{\alpha-1} d u
$$

To determine the ordinates and weight factors for the Gaussian quadrature of the above integral we need to find the zeros of that set of polynomials $\mathcal{F}_{n}(\alpha, u)$ which are orthogonal on $(0,1)$ with respect to $u^{\alpha-1}$ as weighting function. These polynomials therefore satisfy the relation

$$
\int_{0}^{1} u^{\alpha-1} \mathfrak{F}_{m}(\alpha, u) F_{n}(\alpha, u) d u=0
$$

whenever $m \neq n$. They belong to a more general class of orthogonal polynomials known as the Jacobi Polynomials which satisfy a similar orthogonality relationship with respect to the weighting function

$$
u^{\alpha-1}(1-u)^{\alpha-\gamma}
$$

The first four Jacobi polynomials for the case $\alpha=\gamma$ are given below :

$$
\begin{aligned}
& \mathcal{F}_{0}(\alpha, u)=1, \\
& \mathcal{F}_{1}(\alpha, u)=1-\frac{\alpha+1}{\alpha} u, \\
& \mathcal{F}_{2}(\alpha, u)=1-2 \frac{\alpha+2}{\alpha} u+\frac{(\alpha+2)(\alpha+3)}{\alpha(\alpha+1)} u^{2}, \\
& \mathcal{F}_{3}(\alpha, u)=1-3 \frac{\alpha+3}{\alpha} u+3 \frac{(\alpha+3)(\alpha+4)}{\alpha(\alpha+1)} u^{2}
\end{aligned}
$$

$$
-\frac{(\alpha+3)(\alpha+4)(\alpha+5)}{\alpha(\alpha+1)(\alpha+2)} u^{3} .
$$

The general expression for $\mathcal{F}_{n}$ is readily deduced by induction. All zeros of the $\mathcal{F}_{n}$ are real and lie in the interval $0<u<1$. Further, if $u_{i}$ is any such zero, and if

$$
H_{i}=\frac{1}{F_{n}{ }^{\prime}\left(u_{i}\right)} \int_{0}^{1} \frac{u^{\alpha-1} \mathscr{F}_{n}(u)}{u-u_{i}} d u,
$$

then the integral 


$$
\int_{0}^{1} \phi(u) u^{\alpha-1} d u
$$

is approximated by

$$
H_{1} \phi\left(u_{1}\right)+H_{2} \phi\left(u_{2}\right)+\cdots+H_{n} \phi\left(u_{n}\right),
$$

and the approximation coincides with the exact value if $\phi$ is a polynomial of degree $(2 n-1)$ or less.

Since the most frequently encountered value for $\alpha$ in Abel's equation is $\frac{1}{2}$, the ordinates and weight factors for this case are listed in Table A1, Appendix 1, to ten places, for $n=1$ up to $n=8$. The following example illustrates their use and also demonstrates the accuracy obtainable with relatively few ordinates. The equation considered is

$$
\int_{0}^{x}(x-t)^{-1 / 2} g(t) d t=e^{x}
$$

for which the explicit solution is

$$
\pi g(x)=x^{-1 / 2}\left[1+2 x^{1 / 2} e^{x} \int_{0}^{x^{1 / 2}} e^{-t^{2}} d t\right] .
$$

For this example, Equation (4) takes the form

$$
\pi g(x)=x^{-1 / 2}\left[e^{x}+\frac{1}{2} \int_{0}^{1}\left(\frac{e^{x}-e^{x(1-t)}}{t}\right) t^{-1 / 2} d t\right] .
$$

Table 1 gives the results using the Gaussian coefficients for selected values of $n$ TABLE 1 $\pi g(x)$ as found from Equation (14)

\begin{tabular}{c|c}
\hline$x^{1 / 2}$ & $\pi g(x)$ \\
\hline .5 & 3.184593 \\
1.0 & 5.060157 \\
1.5 & 16.9132453 \\
\hline
\end{tabular}

as well as the more exact values calculated from Equation (14). This table illustrates the high degree of precision which is attainable by the use of the present method.

Applied Mathematics Research Laboratory

Aerospace Research Laboratories

Office of Aerospace Research

Wright-Patterson Air Force Base, Ohio

1. F. G. Tricomi, Integral Equations, Interscience, New York, 1957.

2. E. L. KAPLAN, "Numerical integration near a singularity," J. Math. and Phys., v. 31, 1952, p. 1-28.

3. F. B. Hildebrand, Introduction to Numerical Analysis, McGraw-Hill, New York, 1956. 
TABLE 1-Continued

Calculation of $g(x)$ from Equation (15)

$x=.25$

\begin{tabular}{|c|c|c|c|}
\hline & $t_{i}$ & $\phi\left(t_{i}\right)$ & $H_{i}$ \\
\hline $\begin{array}{l}\text { one } \\
\text { point }\end{array}$ & .3333333 & 3079950 & $\begin{array}{c}2 \\
\pi g(x)=3.184040\end{array}$ \\
\hline $\begin{array}{l}\text { two } \\
\text { points }\end{array}$ & $\begin{array}{l}.1155871 \\
.7415557\end{array}$ & $\begin{array}{l}.3164127 \\
.2930075\end{array}$ & $\begin{array}{c}1.3042903 \\
.6257097 \\
\pi g(x)=3.1845929\end{array}$ \\
\hline \multicolumn{4}{|c|}{$x=1.0$} \\
\hline $\begin{array}{l}\text { one } \\
\text { point }\end{array}$ & .3333333 & 2.311644 & $\begin{array}{c}2 \\
\pi g(x)=5.029920\end{array}$ \\
\hline $\begin{array}{l}\text { two } \\
\text { points }\end{array}$ & $\begin{array}{l}.1155871 \\
.7415557\end{array}$ & $\begin{array}{l}2.567064 \\
1.919435\end{array}$ & $\begin{array}{c}1.3042903 \\
.6957097 \\
\pi g(x)=5.060161\end{array}$ \\
\hline $\begin{array}{l}\text { three } \\
\text { points }\end{array}$ & $\begin{array}{l}.0569391 \\
.4371978 \\
.8694994\end{array}$ & $\begin{array}{l}2.6423418 \\
2.2019707 \\
1.8158532\end{array}$ & $\begin{array}{c}.9358279 \\
.7215231 \\
.3426490 \\
\pi g(x)=5.060157\end{array}$ \\
\hline \multicolumn{4}{|c|}{$x=2.25$} \\
\hline $\begin{array}{l}\text { two } \\
\text { points }\end{array}$ & $\begin{array}{l}.1155871 \\
.7415557\end{array}$ & $\begin{array}{l}18.797264 \\
10.382250\end{array}$ & $\begin{array}{c}1.3042903 \\
.6957097 \\
\pi g(x)=16.90520 \\
\end{array}$ \\
\hline $\begin{array}{l}\text { three } \\
\text { points }\end{array}$ & $\begin{array}{l}.0569391 \\
.4371978 \\
.8694994\end{array}$ & $\begin{array}{r}20.03654 \\
13.58656 \\
9.36913\end{array}$ & $\begin{array}{c}.9358279 \\
.7215231 \\
.3426490 \\
\pi g(x)=16.91319\end{array}$ \\
\hline $\begin{array}{l}\text { four } \\
\text { points }\end{array}$ & $\begin{array}{l}.0336483 \\
.2761843 \\
.6346775 \\
.9221560\end{array}$ & $\begin{array}{r}20.55933 \\
15.89908 \\
11.36443 \\
8.99664\end{array}$ & $\begin{array}{c}.7253676 \\
.6274133 \\
.4947621 \\
.2024571 \\
\pi g(x)=16.91325\end{array}$ \\
\hline
\end{tabular}




\section{APPENDIX 1}

TABLE A1

Ordinates and weights for Gaussian quadrature with weight function $x^{-1 / 2}$

\begin{tabular}{|c|c|c|c|}
\hline & & $x_{i}$ & $H_{i}$ \\
\hline$n=1$ & 1 & .3333333333 & 2.0000000000 \\
\hline$n=2$ & $\begin{array}{l}1 \\
2\end{array}$ & $\begin{array}{l}.1155871100 \\
.7415557471\end{array}$ & $\begin{array}{r}1.3042903097 \\
.6957096903\end{array}$ \\
\hline$n=3$ & $\begin{array}{l}1 \\
2 \\
3\end{array}$ & $\begin{array}{l}.0569391160 \\
.4371978528 \\
.8694993949\end{array}$ & $\begin{array}{ll}.93582 & 78691 \\
.72152 & 31461 \\
.34264 & 89848\end{array}$ \\
\hline$n=4$ & $\begin{array}{l}1 \\
2 \\
3 \\
4\end{array}$ & 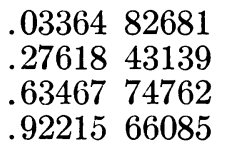 & 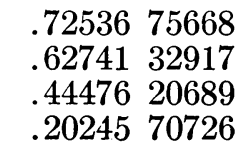 \\
\hline$n=5$ & $\begin{array}{l}1 \\
2 \\
3 \\
4 \\
5\end{array}$ & 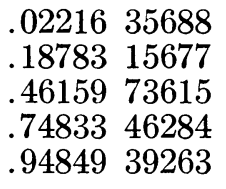 & $\begin{array}{ll}.59104 & 84494 \\
.53853 & 34386 \\
.43817 & 27251 \\
.29890 & 26983 \\
.13334 & 26886\end{array}$ \\
\hline$n=6$ & $\begin{array}{l}1 \\
2 \\
3 \\
4 \\
5 \\
6\end{array}$ & 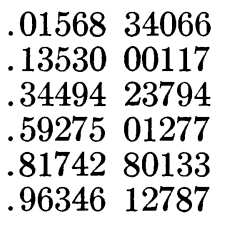 & 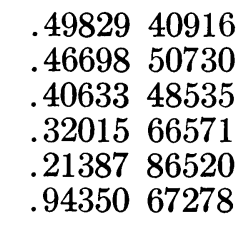 \\
\hline$n=7$ & $\begin{array}{l}1 \\
2 \\
3 \\
4 \\
5 \\
6 \\
7\end{array}$ & 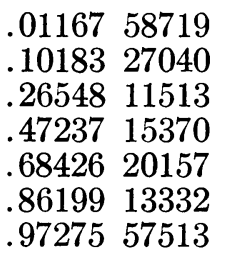 & $\begin{array}{ll}.43052 & 77068 \\
.41039 & 62274 \\
.37107 & 67950 \\
.31440 & 63344 \\
.24303 & 71414 \\
.16031 & 61744 \\
.70238 & 92066\end{array}$ \\
\hline$n=8$ & $\begin{array}{l}1 \\
2 \\
3 \\
4 \\
5 \\
6 \\
7 \\
8\end{array}$ & 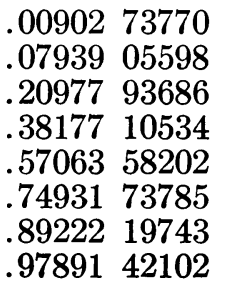 & 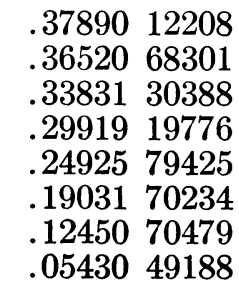 \\
\hline
\end{tabular}

